\title{
Caracterização e alterações morfológicas em grãos de pólen de fisális (Physalis peruviana L. (Solanaceae)) cultivada sob diferentes espectros luminosos
}

\author{
Daniel Fernandes da Silva ${ }^{1}$, Fabíola Villa ${ }^{2}$, Luciana Sabini da Silva ${ }^{2}$, Giordana Menegazzo da Silva ${ }^{2}$, Alesson \\ Felipe Eckert ${ }^{2}$ \\ ${ }^{1}$ Universidade do Oeste Paulista - UNOESTE, Agronomia, Presidente Prudente, SP. ${ }^{2}$ Universidade Estadual do Oeste do \\ Paraná - UNIOESTE, Pós-Graduação em Agronomia. E-mail: daniel eafi@yahoo.com.br
}

\section{Resumo}

Physalis peruviana L. é uma espécie de interesse comercial pertencente à família Solanaceae, cultivada preferencialmente em ambiente sombreado, que ainda apresenta cultivo restrito a pequenas áreas no Brasil e por isso demanda estudos mais aprofundados. As plantas são diretamente afetadas por fatores ambientais tais como estresse hídrico, temperatura, radiação, dentre outros. Estes fatores afetam não só os órgãos vegetativos, mas também estruturas reprodutivas, podendo acarretar danos às plantas agronomicamente exploradas. Diante da necessidade de sombreamento apresentado pela cultura o presente trabalho objetivou caracterizar o grão de pólen e verificar a influência de malhas fotoconversoras utilizadas no sombreamento sobre a morfologia dos grãos de pólen desta espécie. $O$ trabalho foi desenvolvido na Universidade Federal de Lavras, onde três repetições de duas plantas foram cultivadas a pleno sol e sob malhas fotoconversoras nas colorações branca, azul, vermelha e preta. O pólen de flores em antese foi coletado, processado e fotografado em microscópio eletrônico de varredura (MEV). O diâmetro polar, diâmetro equatorial e área do pólen foram medidos em dez grãos de pólen. Os resultados demonstraram que grãos de pólen de $P$. peruviana são isopolares, radiais, de formato prolato-esferoidal e tamanho mediano. Também verificou-se aumento da área do grão de pólen quando cultivado em sombreamento com malha fotoconversora branca e a pleno sol.

Palavras-chave: microclima; microgametogênese; Physalis peruviana L.; radiação; reprodução sexuada.

\section{Characterization and morphological changes in cape gooseberry (Physalis peruviana L. (Solanaceae))} pollen grains cultivated under different light spectrum

\begin{abstract}
Physalis peruviana $\mathrm{L}$. is a species of commercial interest belonging to the Solanaceae family, cultivated preferentially in shaded environment, which still has cultivation restricted to small areas in Brazil and therefore requires further studies. Plants are directly affected by environmental factors such as drought, temperature, radiation, among others. These factors affect not only the vegetative organs, but also reproductive structures, which may cause damage to agronomically explored plants. With the need for shading presented by the crop, the present work aimed to characterize the pollen grain and to verify the influence of shade nets used in shading on the morphology of pollen grains of this species. The work was developed at the Lavras Federal University, where three replications of two plants were cultivated under full sun and under shadenets white, blue, red and black. Flower anthesis pollen was collected, processed and photographed by scanning electron microscope (SEM). Polar diameter, equatorial diameter and pollen area were measured in ten pollen grains. The results showed that $P$. peruviana pollen grains are isopolar, radial, prolato-spheroidal in shape and medium in size. There was also an increase in pollen grain area when cultivated in shading with white shade net and in full sun.
\end{abstract}

Keywords: microclimate; microgametogenesis; Physalis peruviana L.; radiation; sexual reproduction. 


\section{Introdução}

Fisális (Physalis sp.) é um fruto considerado exótico, pertencente ao grupo das pequenas frutas, que vem ganhando cada vez mais importância por suas inúmeras propriedades medicinais e nutricionais (LIMA, 2009a). O gênero Physalis pertence à família Solanaceae e possui aproximadamente cem espécies, facilmente identificáveis por seu cálice concrescido e permanente que envolve o fruto durante todo seu período de crescimento e maturação (SOARES et al., 2009).

A maioria das espécies de Physalis possuem caracteres herbáceos, e encontram-se distribuídos por diversos continentes do mundo, principalmente nas regiões tropicais e subtropicais, desde o sul da América do Norte até a América do Sul (NURIT-SILVA; AGRA, 2005). Segundo Castañeda (1961), espécies de Physalis L. são, em sua maioria, plantas de ambiente sombreado ou meia luz, o que infere a necessidade de sombreamento quando exploradas em plantios comerciais. Entre as espécies pertencentes ao gênero, a principal espécie cultivada é a Physalis peruviana L., com grande valor econômico, atingindo o segundo lugar na pauta de exportações na Colômbia, maior produtor mundial da fruta (MÁRQUEZ et al., 2009).

O sombreamento com malhas é uma ferramenta amplamente utilizada na olericultura, pois minimiza os efeitos da temperatura e da luminosidade excessiva sobre as plantas (SEABRA JÚNIOR et al., 2012). O emprego de malhas para simples sombreamento ou ainda para potencialização da produtividade por meio do controle do espectro luminoso incidente sobre as plantas gera microclimas diferenciados, aos quais as plantas respondem amplamente por meio de modificações químicas na composição de seus metabólitos secundários e em sua estrutura anatômica.

Devido à variedade de malhas de sombreamento existente, a escolha do tipo de malha ideal para cada cultura, de acordo com seu percentual de sombreamento e propriedades físicas de transmissão da luz sobre elas incidente, é fundamental para garantir um microclima propício ao desenvolvimento do vegetal e desta forma, garantir o sucesso da produção (SEABRA JÚNIOR et al., 2012; SHAHAK et al., 2004).

Silva et al. (2016a) relatam que o sombreamento com telas de diferentes colorações modificam a composição química de frutos de diferentes espécies de fisális quanto a presença de antocianinas, fenólicos totais, ação antioxidante, dentre outros componentes. Em outro estudo Silva et al. (2016b) relatam que mudas de Physalis L. com melhor qualidade para cultivo comercial, em relação a conformidade morfoanatômica das mudas, devem ser obtidas sobre sombreamento com qualidade de luz diferenciada de acordo com a espécie.

Apesar da existência de estudos a respeito da qualidade de luz para plantas cultivadas, em especial para o gênero Physalis, Zinn et al. (2010) relatam que estresses causados por temperatura e luz são amplamente estudados em órgãos vegetativos, e que, embora também exerçam impacto sobre a reprodução sexual das plantas, esta é estudada em menor escala em órgãos reprodutivos, devido a complexidade de desenvolvimento dos gametas e do processo de fertilização, além dos mesmos ocorrerem em um curto espaço de tempo e ainda encontrarem-se em regiões mais protegidas da flor.

A exemplo desse efeito das condições ambientais sobre as estruturas reprodutivas Ledesma e Sugiyama (2005) apresentam estudo em que o comprometimento do grão de pólen de morango pode ser visualizado em temperatura mais altas, o que está correlacionado ao comprimento de onda incidente sobre a planta matriz e Stanley e Linskens (1974) descrevem o efeito de luz sobre a degradação do grão de pólen. Braidwood et al. (2014) relatam que o comprimento das ondas incidentes sobre a planta estão correlacionadas com 0 alongamento celular, pois a luz além de fonte de energia para os vegetais atua também como fotossinalizador (HOYO et al., 2014).

Além disso, o conhecimento sobre a morfologia polínica é crucial para a preservação e melhoramento genético de muitas espécies, além de auxiliar na manutenção da conservação de pólen que pode ser usado em pesquisas, testes alergênicos, auxiliar na reastreabilidade e conservação de germoplasmas (SOUZA et al., 2015; VOLK, 2011). Ainda segundo Knox (1984), o conhecimento sobre a morfologia do grão de pólen de uma espécie permite identificar alterações que possam comprometer o sucesso reprodutivo quando alterações morfológicas ocorrerem.

Diante do exposto, o presente trabalho teve como objetivo caracterizar o grão de pólen de Physalis peruviana L. e posteriormente 
verificar a influência do sombreamento sobre a morfologia do pólen.

\section{Material e Métodos}

As plantas foram cultivadas em área experimental pertencente ao Departamento de Agricultura (DAG) da Universidade Federal de Lavras (UFLA), localizado na cidade de Lavras, sul de Minas Gerais.

As coordenadas geográficas do local de implantação do cultivo são $21^{\circ} 14^{\prime}$ de latitude sul, 45으 de longitude oeste e $918 \mathrm{~m}$ de altitude. 0 clima local é do tipo Cwa, segundo a classificação de Köeppen (ALVAREZ et al., 2013), temperado chuvoso (mesotérmico) com inverno seco e verão chuvoso, subtropical, com inverno seco e temperatura do mês mais quente maior que $22^{\circ} \mathrm{C}$ $\left(22,1^{\circ} \mathrm{C}\right.$ em fevereiro), o que caracteriza uma região subtropical com estiagem de inverno. Em termos anuais, a precipitação pluvial média é de $1.529,7 \mathrm{~mm}$ e a temperatura média anual é $19,4^{\circ} \mathrm{C}$, variando de $15,8^{\circ} \mathrm{C}$ em julho a $22,1^{\circ} \mathrm{C}$ em fevereiro (BRASIL, 1992; DANTAS et al., 2007).

O sombreamento sobre as plantas foi feito com malhas fotoconversoras Cromatinet $^{\circ} \mathrm{da}$ marca Polysack com 50\% de sombreamento, em quatro colorações diferentes: branca, azul, vermelha e preta, presas sobre estrutura de madeira, removível, de $3 \times 3 \times 1,5$ metros de largura, comprimento e altura, respectivamente, além de um tratamento testemunha em que as plantas permaneceram a pleno sol.

As sementes de $P$. peruviana foram adquiridas de cultivos na Universidade Estadual do Oeste do Paraná (Unioeste), Campus de Marechal Cândido Rondon, Paraná, colhidas na safra 2013/2014. Foram semeadas em bandejas de isopor de 128 células, uma semente por célula dispensando raleio. O substrato utilizado foi uma mistura de solo (Latossolo Vermelho distroférrico argiloso característico da região) + substrato

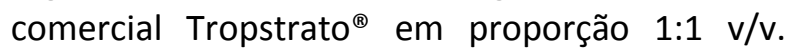
Após semeadas as bandejas foram irrigadas e colocadas sob as malhas, para germinação.

Ao atingirem condições ideais de transplantio, com 60 dias de idade, as mudas foram transplantadas em vasos de 6 litros para que continuassem seu desenvolvimento até a fase produtiva. Cada muda permaneceu sobre a mesma coloração de malha em que foi germinada. $O$ substrato utilizado para preenchimento dos vasos foi uma mistura de solo (Latossolo vermelho distroférrico argiloso característico da região) + esterco de curral na proporção 7:3 v/v, enriquecido com NPK conforme análise prévia de solo.

As plantas receberam acompanhamento fitotécnico semelhante à cultura de solanáceas convencionais devido à escassez de informação na literatura para a cultura do fisális e a irrigação foi diária conforme necessidade das plantas.

Ao atingirem idade adulta, quando todos os tratamentos estavam em plena floração, três flores de cada planta foram retiradas, totalizando 18 flores por tratamento, e deixadas 12 horas em placa de Petri para liberação do pólen. Devido a estrutura rígida apresentada por grãos de pólen, o preparo das amostras para observação em microscopia eletrônica de varredura iniciou-se com a montagem dos stubs de alumínio, com dispersão dos grãos de pólen sobre os mesmos. Em seguida foram levados para Sputtering para banho de ouro aumentando a condutividade. Com as amostras prontas, as mesmas foram observadas em Microscópio Eletrônico de Varredura (MEV) LEO EVO 40 XVP onde foram captadas as imagens. Uma amostra composta pela mistura de pólen das três repetições foi analisada e fotografada. Vinte fotos de cada amostra foram retiradas e foram medidos o diâmetro longitudinal (DL), diâmetro transversal (DT) e área de vinte grãos de pólen. Além das medições descritas acima, para a descrição morfológica dos grãos de pólen da espécie póléns obtidos de plantas em condição natural de cultivo (sem sombreamento) foram utilizados.

O delineamento experimental foi em blocos casualizados, sendo uma espécie de fisális $(P$. peruviana) sob cinco condições de sombreamento (malha branca, azul, vermelha e preta, além da condição de pleno sol). Cada tratamento foi composto por três repetições de duas plantas dispostos aleatoriamente sob cada condição de sombreamento.

Os dados quantitativos obtidos foram submetidos ao teste de normalidade e posteriormente à análise de variância pelo programa estatístico SISVAR (FERREIRA, 2011) e as médias comparadas pelo teste de Scott-Knott ao nível de $5 \%$ de probabilidade.

\section{Resultados e Discussão}

Os grãos de pólen de $P$. peruviana classificam-se como mônades de tamanho médio, já que os mesmos se encontram na faixa entre 25-50 $\mu \mathrm{m}$ de diâmetro. Tais resultados concordam em relação ao tamanho com o trabalho de Barth e Duarte (2008), que 
encontraram no estudo com diferentes gêneros de Solanaceae polens de tamanho mediano, embora esta não seja uma característica atribuída a todos os táxons dentro da família.

Variações no tamanho dos grãos de pólen podem ser encontradas, passando de muito pequenos, como em algumas espécies de Cestrum estudadas por Silva et al. (2003) a grande como em Brunfelsia hydrangeiformis (Pohl) Benth (BATISTA-FRANKLIN; GONÇALVES ESTEVES, 2002). Ressalta-se ainda que o tamanho dos grãos de pólen de $P$. peruviana estão em conformidade com a descrição de Erdtman (1952) que relata que grãos de pólen de espécies pertencente à família Solanaceae apresentam entre 14,5 e $61 \mu \mathrm{m}$ e assemelham-se aos resultados encontrados por El-Ghamery et al. (2018) que também relataram grãos de pólen de $P$. peruviana como sendo de tamanho mediano.

Grãos de pólen de $P$. peruviana podem ser classificados como prolato-esferoidais, com média da relação DP/DE de $1,04 \mu \mathrm{m}$. Os resultados aqui encontrados corroboram CruzBarros et al. (2011) que relatam relação DP/DE idêntica à encontrada neste estudo para a mesma espécie. Apesar do mesmo formato encontrado em ambos os estudos, para outras espécies de Physalis o formato dos grãos de pólen pode variar, diferindo entre as espécies. Como exemplo podemos citar a variação de 0,87 a 1,20 $\mu \mathrm{m}$ de relação DP/DE em grãos de pólen de Physalis divaricata D. Don, descrita por Perveen e Qaiser (2007), afirmando que a forma dos grãos de pólen para esta espécie varia de oblato-esferoidal a sub-prolato, passando pelo formato prolato-esferoidal; formato oblatoesferoidal descrito por Cruz-Barros et al. (2011) para Physalis viscosa L.; e formato prolatoesferoidal em Physalis minima L. (PRABHAKAR; RAMAKRISHNA, 2014).

Barth e Duarte (2008), estudando a palinologia de diferentes espécies arbóreas de Solanaceae pertencentes à flora Catarinense, verificaram que dentro do gênero Solanum $\mathrm{L}$. ocorre diferença no formato do grão de pólen entre as espécies. Corroborando esta ideia, Silva et al. (2003) também citam o formato prolatoesferoidal para quatro, de doze espécies do gênero Cestrum L. estudadas, descrevendo a ocorrência de quatro formas diferentes de pólen entre as espécies de Cestrum. Com base nesses relatos, juntamente com a variação descrita entre as espécies de Physalis, observa-se uma grande variação de formas de grãos de pólen entre gêneros e até mesmo entre espécies pertencentes ao mesmo gênero dentro de Solanaceae.

De acordo com a definição dada por Ybert et al. (1992) os grãos de pólen de $P$. peruviana deste estudo podem ser classificados como isopolares, por possuírem um único plano de corte em que ambos os lados permanecem simétricos e, ainda, diâmetros polar e equatorial com comprimentos distintos. Em geral, grãos de pólen isopolares estão presentes em grande número de espécies e gêneros desta família, a exemplo de dez espécies de Nicotiana estudadas por Collao-Alvarado et al. (2016), vinte e três espécies de Cestrum palinologicamente descritas por Vignoli-Silva et al. (2015); seis espécies de Solanum ocorrentes na Arábia Saudita (LASHIN, 2011); cinco espécies de Capsicum (MARTINS et al., 2013); e seis espécies de Brunfelsia (BATISTAFRANKLIM; GONÇALVES-ESTEVES, 2002).

O pólen de $P$. peruviana também pode ser classificado como radial, o que está de acordo com o táxon no qual se insere o gênero, pois dentro da família solanaceae pode-se observar predominância de espécies com pólen de simetria radial (HIERRO et al., 2016; STANSKI, 2014; LASHIN, 2011). Também Barth e Duarte (2008) relatam simetria radial como característica compartilhada entre espécies dos gêneros Acnistus, Aureliana, Brunfelsia, Capsicum, Cestrum e Solanum, todas encontradas no estado de Santa Catarina, Brasil. A simetria radial encontrada neste trabalho também corrobora Burbano et al. (2005) que se referem a grãos de pólen de $P$. peruviana como mônades isopolares, de simetria radial.

Após análise de todas as características externas avaliadas os grãos de pólen de $P$. peruviana pode ser classificados como medianos, de forma prolato-esferoidal, isopolares e com simetria radial (Figura 1A) (Erdman, 1952).

Foram encontradas diferenças significativas para diâmetro polar, diâmetro equatorial e área de grãos de pólen de Physalis peruviana L. cultivados sobre diferentes malhas fotoconversoras, embora estes dados não alterem a classificação morfológica do pólen pois estas plantas foram submetidas a condições especiais, fugindo portanto da condição natural da espécie. Nos tratamentos a pleno sol e sob malha branca os grãos de pólen apresentaram maior diâmetro transversal e área em relação aos demais tratamentos (Tabela 1, Figura 1). 
Tabela 1. Diâmetro polar, diâmetro equatorial e área de grãos de pólen de Physalis peruviana L. cultivados sobre diferentes malhas fotoconversoras. UFLA, 2014.

\begin{tabular}{lccc}
\hline \multicolumn{1}{c}{ Sombreamento } & Diâmetro polar $(\mu \mathrm{m})$ & Diâmetro equatorial $(\mu \mathrm{m})$ & Área do pólen $(\mu \mathrm{m})$ \\
\hline Pleno sol & $27,55 \mathrm{a}^{*}$ & $26,33 \mathrm{~b}$ & $552,09 \mathrm{a}$ \\
Malha branca & $30,90 \mathrm{a}$ & $27,42 \mathrm{~b}$ & $598,51 \mathrm{a}$ \\
Malha azul & $24,80 \mathrm{~b}$ & $26,83 \mathrm{~b}$ & $494,26 \mathrm{~b}$ \\
Malha vermelha & $24,21 \mathrm{~b}$ & $28,32 \mathrm{~b}$ & $497,45 \mathrm{~b}$ \\
Malha preta & $22,07 \mathrm{~b}$ & $32,21 \mathrm{a}$ & $524,62 \mathrm{~b}$ \\
\hline \multicolumn{1}{c}{ CV (\%) } & 7,37 & 6,95 & 5,71 \\
\hline
\end{tabular}

*Letras minúsculas diferem entre si na coluna pelo teste de Skott-Knott a 5\% de probabilidade.

Figura 1: Grãos de pólen de Physalis peruviana L. cultivada à pleno sol $(A)$ e sobre malha fotoconversora branca (B), azul (C), vermelha (D) e preta (E). UFLA, 2012.
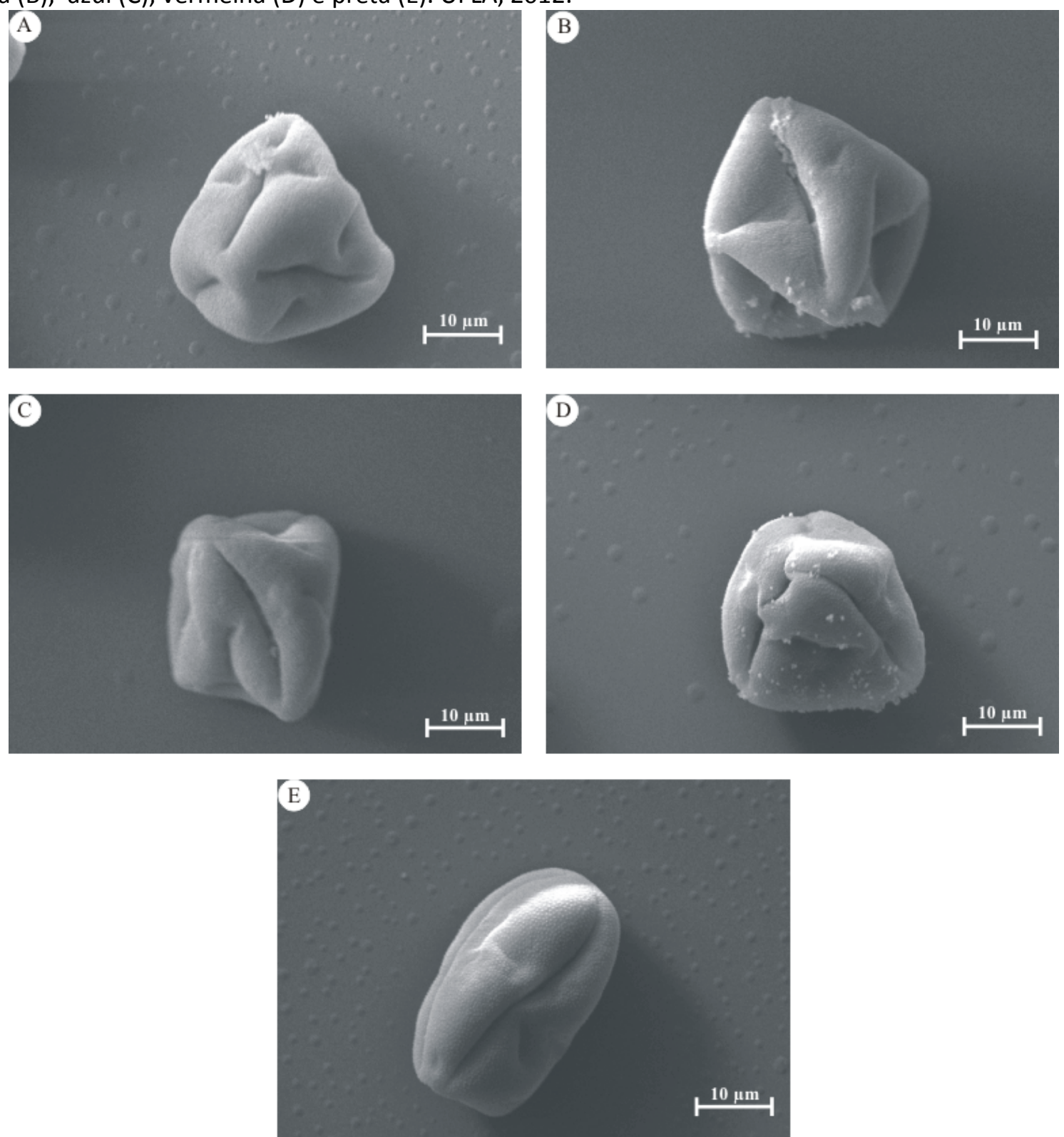

Os tratamentos que apresentaram maior diâmetro polar e área foram os que, segundo a literatura estão mais sujeitos a ação da radiação solar e também de elevadas temperaturas. 0 aumento do diâmetro polar e da área pode estar associado a um aumento na espessura da exina, uma vez que esta funciona como uma camada protetora do pólen à radiação solar, dissecação e ao ataque de patógenos (DOBRITSA et al., 2009). 
Outro fator importante que deve ser levado em consideração segundo Vieira (2013) é o estágio de desenvolvimento da flor, flores em antese, por já se encontrarem com os verticilos estéreis completamente abertos e mais próximas do momento de liberação do pólen, conferem menor proteção à estes, havendo necessidade de espessamento da exina nessa fase, principalmente quando estas plantas encontramse sobre condições ambientais desfavoráveis, o que foi o caso das plantas de $P$. peruviana expostas à maior radiação nos tratamentos a pleno sol e sobre malha fotoconversora branca.

No tratamento a pleno sol, outro fator que pode ter provocado o espessamento da exina levando os grãos de pólen a ter maior área é a maior possibilidade de dessecação devido às altas temperaturas incidentes sobre as plantas. Altas temperaturas e seca afetam a formação de órgãos reprodutivos, por indução da esterilidade polínica. A produção de grãos de pólen é particularmente reduzida por altas temperaturas e seca, não somente no período quando as células mãe do micrósporo são formadas no tecido arqueosporial das anteras, mas também durante a antese e fertilização. Nessa fase de desenvolvimento, o pólen também é sensível a intensidade luminosa (PETR, 1988).

Um outro fator que pode justificar a maior área de grãos de pólen em condição de pleno sol é o aparecimento de vacúolos armazenadores de água que atuam como ferramenta adaptativa de tolerância ao défcit hídrico devido a uma menor disponibilidade de água no ambiente, em função de temperaturas mais amenas a pleno sol (PACINI et al., 2011).

Apesar de poucos relatos na literatura a respeito do efeito da radiação sobre a morfologia polínica, outros autores relatam que houve diferença da estrutura de grãos de pólen quando submetidas a condições adversas. Exemplos dessas modificações são dados por alteração do tamanho do grão de pólen de algodão (Gossypium hirsutum L.) submetido a diferentes intensidades de radiação gama (Savașkan, 2002) e de anomalias verificadas em grãos de pólen de soja expostos a elevadas intensidades de radiação AV-B (KOTI et al., 2004).

De forma geral, os resultados encontrados contribuem para ampliar 0 conhecimento sobre a biologia floral em $P$. peruviana, um estudo importante quando se trata de uma planta explorada economicamente e com avanço ainda incipiente na área de melhoramento genético. Informações sobre modificações no grão de pólen desta espécie quando a planta matriz está submetida a fatores ambientais adversos concordam com afirmações de pesquisadores da área de anatomia e morfologia de órgãos reprodutivos vegetais e, ao mesmo tempo, confronta a pouca literatura existente sobre $o$ assunto.

Conhecer a morfologia do pólen em condições naturais é importante pois nos permite identificar visualmente alterações que podem refletir em problemas reprodutivos em plantas submetidas a tratos culturais específicos como o sombreamento artificial, por exemplo.

A partir da observação de modificações anatômicas causadas pelo sombreamento nos grãos de pólén de $P$. peruviana surgem novas demandas de estudos mais aprofundados nessa e em outras espécies do gênero para melhor compreensão dos efeitos dessas modificações morfológicas sobre a germinação e funcionalidade do grão de pólen durante a fecundação e desenvolvimento do vegetal oriundo desse processo.

\section{Conclusões}

O pólen de Physalis peruviana L. é isopolar, radial, prolato-esferoidal de tamanho mediano em condições naturais de cultivo.

O sombreamento das plantas com malhas fotoconversoras altera a morfologia externa do grão de pólen de Physalis peruviana L.

\section{Referências}

ALVAREZ, C. A.; STAPE, J. L.; SENTELHAS, P. C.; GONÇALVES, J. L. M.; SPAROVEK, G. Köppen's climate classification map for Brazil. Meteorologische Zeitschrift, v.22, n.6, p. 711728, 2013. https://doi.org/10.1127/09412948/2013/0507

BARTH, O. M.; DUARTE, S. G. Morfologia polínica de espécies arbóreas de Solanaceae do Estado de Santa Catarina, Brasil. Hoehnea, v.35, n.3, p. 379386, 2008. http://dx.doi.org/10.1590/S2236$\underline{89062008000300005}$

CASTAÑEDA, R. Frutas silvestres de Colombia. Bogota: Editora San Juan Eudes, 1961. 342 p.

BATISTA-FRANKLIM, C. P. R.; GONÇALVESESTEVES, V. Morfologia polínica de espécies de Brunfelsia L. (Solanaceae) ocorrentes no Estado do Rio de Janeiro. Revista Brasileira de Botânica, 
v.25, n.2, p. 137-145, 2002.

http://dx.doi.org/10.1590/S0100$\underline{84042002000200003}$

BRAIDWOOD, L.; BREUER, C.; SUGIMOTO, K. My body is a cage: mechanisms and modulation of plant cell growth. New Phytologist, v.201, n.2, p. 388-402, 2014.

https://doi.org/10.1111/nph.12473

BRASIL. Ministério da Agricultura e da Reforma Agrária. Departamento Nacional de Meteorologia. Normais climatológicas: 19611990. Brasília, DF: Ministério da Agricultura, 1992. $84 \mathrm{p}$.

BURBANO, T. C. L.; CAETANO, C.; VALLEJO, F. A.; MUÑOZ, J. E.; CRIOLLO, H.; OLAYA, C. Physalis peruviana L. and Physalis philadelphica Lam. palynological characterization and pollen viability. Agronomia colombiana, v.23, n.1, p. 55-61, 2005.

COLLAO-ALVARADO, K.; PLANELLA, M. T.; NIEMEYER, $H$. M. El polen de especies del género Nicotiana (Solanaceae) presentes en Chile: evaluación de la utilidad de sus caracteres morfológicos como biomarcadores en estudios arqueológicos. Boletin de la Sociedad Argentina de Botanica, v.51, n.1, p. 135-152, 2016. https://doi.org/10.31055/1851.2372.v51.n1.1442 $\underline{3}$

CRUZ-BARROS, M. A. V.; SILVA, E. L.; GASPARINO, E. C.; SOUZA, L. N.; OLIVEIRA, A. C. Flora Polínica da Reserva do Parque Estadual das Fontes do Ipiranga (São Paulo, Brasil). Família: 136Solanaceae. Hoehnea, v.38, n.4, p. 661-685, $2011 . \quad$ https://doi.org/10.1590/S223689062011000400008

DANTAS, A. A. A.; CARVALHO, L. G.; FERREIRA, L. Classificação e tendências climáticas em Lavras, MG. Ciência e Agrotecnologia, v.31, n.6, p. 18621866, 2007. http://dx.doi.org/10.1590/S1413$\underline{70542007000600039 \mathrm{v}}$

DOBRITSA, A. A.; NISHIKAWA, S. I.; PREUSS, D.; URBANCZYK-WOCHNIAK, E.; SUMNER, L. W.; HAMMOND, A.; CARLSON, A. L.; SWANSON, R. J. LAP3, a novel plant protein required for pollen development, is essential for proper exine formation. Sexual Plant Reproduction, v.22, n.167, 2009. http://dx.doi.org/10.1007/s00497$\underline{009-0101-8}$
EL-GHAMERY, A. A.; KHAFAGI, A. A. F.; RAGAB, O. G. Taxonomic implication of pollen morphology and seed protein electrophoresis of some species of solanaceae in Egypt. Al Azhar Bulletin of Science, v.29, n.1, p. 43-56, 2018.

https://doi.org/10.21608/absb.2018.33757

ERDTMAN, G. Pollen morphology and plant taxonomy. Angiosperms. Journal Geologiska Föreningen i Stockholm Förhandlingar, v.74, n.4, p. 526-527, 1952.

https://doi.org/10.1080/11035895209453507

FERREIRA, D. F. SISVAR: A computer statistical analysis system. Ciência e Agrotecnologia, Lavras, v.35, n.6, p. 1039-1042, 2011.

http://dx.doi.org/10.1590/S1413-

$\underline{70542011000600001}$

HIERRO, A.; GUERRA, S.; PADILLA, F.; ARROYO, C. R.; SORIA, N.; DEBUT, A. Assessing the morphological variations on the pollen grains of Solanum betaceum caused by chemical, biological and ecological pesticides. Biology and medicine, v.8, n.3, p. 1-5, 2016.

http://dx.doi.org/10.4172/0974-8369.1000286

HOYO, Y.; FUJIWARA, K.; HOSHINO, Y. Effects of different wavelengths of LED light on pollen germination and direction of pollen tube elongation in Cyrtanthus mackenii. Advances in Horticultural Science, v.28, n.4, p. 190-194, 2014.

KNOX, R. B. The Pollen Grain. In: JOHRI, B.M. Embryology of angiosperms. Berlin: SpringerVerlag, 1984. p. 197-271.

https://doi.org/10.1007/978-3-642-69302-1 5

KOTI, S.; REDDY, K. R.; KAKANI, V. G.; ZHAO, D.; REDDY, V. R. Soybean (Glycine max) pollen germination characteristics, flower and pollen morphology in response to enhanced ultraviolet$B$ radiation. Annals of Botany, v.94, n.6, p. 855864, 2004. https://doi.org/10.1093/aob/mch212

LASHIN, G. M. A. Palynology of six species of Solanum (Solanaceae). Life Science Journal, v.8, n.4, p. 687-697, 2011.

LEDESMA, N.; SUGIYAMA, N. Pollen quality and performance in strawberry plants exposed to high-temperature stress. Journal of the American Society for Horticultural Science, v.130, n.3, p. 
341-347, 2005.

http://dx.doi.org/10.21273/JASHS.130.3.341

LIMA C. S. M. Fenologia, sistemas de tutoramento e produção de Physalis peruviana na região de Pelotas, RS. 2009. 114 f. Dissertação (Mestrado em Ciências) - Universidade Federal de Pelotas, Rio Grande do Sul. 2009.

MÁRQUEZ, C. J. C., TRILLOS, O. G.; CARTAGENA, J. R. V.; COTES, J. M. T. Evaluación físico-quimica y sensorial de frutos de uchuva (Physalis peruviana L.). Revista de la Facultad de Química Farmacéutica, v.16, n.1, p. 42-48, 2009.

MARTINS, K. C.; SOUZA, S. A. M.; PEREIRA, T. N. S.; RODRIGUES, R.; PEREIRA, M. G.; CUNHA, M. Palynological characterization and genetic divergence between accessions of chilli and sweet peppers. Horticultura brasileira, v.31, n.4, p. 568-573, 2013.

http://dx.doi.org/10.1590/S0102-

$\underline{05362013000400010}$

NURIT-SILVA, K.; AGRA, M. F. Estudo farmacobotânico comparativo entre Nicandra physalodes e Physalis angulata (Solanaceae). Revista Brasileira de Farmacognosia, v.15 n.4, p. 344-351, 2005. http://dx.doi.org/10.1590/S0102$\underline{695 \times 2005000400016}$

PACINI, E.; JACQUARD, C.; CLEMENT, C. Pollen vacuoles and their significance. Planta, v.23, n.2, p. 217-227, 2011.

http://dx.doi.org/10.1007/s00425-011-1462-4

PERVEEN, A.; QAISER, M. Pollen morphology of family solanaceae from Pakistan. Pakistan journal of botany, v.39, n.7, p. 2243-2256, 2007.

PETR, J.; ČERNÝ, V.; HRUŠKA L. Yield formation in cereals. In: PETR, J.; ČERNÝ V.; HRUŠKA L. Yield formation in the main field crops. Amsterdam: Elsevier, 1988. p. 72-153. (Developments in Crop Science, 13). https://doi.org/10.1016/B978-0444-98954-3.50007-X

PRABHAKAR, R.; RAMAKRISHNA, H. Pollen diversity of ethnomedicinal plants of nirmal forest division in Adilabad district, Telangana State, India. World journal of pharmaceutical research, v.3, n.8, p. 220-237, 2014.
SAVAȘKAN, C. The effects of gamma irradiation on the pollen size of Gossypium hirsutum L. Turkish journal of botany, v.26, n.6, p. 477-480, 2002.

SEABRA JÚNIOR, S.; NEVES, S. M. A. S.; NUNES, M. C. M.; INAGAKI, A. M.; SILVA, M. B.; AQUINO, C. R.; DIAMANTE, M. S. Cultivo de alface em Cáceres MT: perspectivas e desafios. Revista Conexão UEPG, v.8, n.1, p. 130-137, 2012.

SHAHAK, Y.; GUSSAKOVSKY, E. E.; COHEN, Y.; LURIE, S. Colornets: A new approach for light manipulation in fruit trees. Acta Horticulturae, v.636, p. 609-616. 2004.

https://doi.org/10.17660/ActaHortic.2004.636.76

SILVA, D. F.; PIO, R.; SOARES, J. D. R.; NOGUEIRA, P. V.; PECHE, P. M.; VILLA, F. Produção de mudas de espécies de Physalis cultivadas sob diferentes colorações de telas fotoconversoras. Acta Scientiarum - Agronomy, v.38, n.2, p. 257-263. 2016b.

http://dx.doi.org/10.4025/actasciagron.v38i2.278 $\underline{93}$

SILVA, D. F.; PIO, R.; SOARES, J. D. R.; ELIAS, H. H. S.; VILLA, F. Light spectrum on the quality of fruits of physalis species in subtropical area. Bragantia, v.75, n.3, p. 371-376, 2016b. https://doi.org/10.1590/1678-4499.463

SILVA, S. N.; CARVALHO, A. M. V.; SANTOS, F. A. R. Morfologia polínica de doze espécies de Cestrum L. (Solanaceae) da mata higrófila na Bahia, Brasil. Acta Scientiarum. Biological Sciences, v.25, n.2, p. 439-443, 2003. http://dx.doi.org/10.4025/actascibiolsci.v25i2.20 $\underline{35}$

SOARES, E. L. C.; VENDRUSCOLO, G. S.; SILVA, M. V.; THODE, V. A.; SILVA, J. G.; MENTZ, L. A. O gênero Physalis L. (Solanaceae) no Rio Grande do Sul, Brasil. Pesquisas, Botânica, n.60, p. 323-340, 2009.

SOUZA, E. H.; SOUZA, F. V. D.; ROSSI, M. L.; BRANCALLEÃO, N.; LEDO, C. A. S.; MARTINELLI, A. $P$. Viability, storage and ultrastructure analysis of Aechmea bicolor (Bromeliaceae) pollen grains, an endemic species to the Atlantic Forest. Euphytica, v.204, n.1, p. 13-28, 2015. https://doi.org/10.1007/s10681-014-1273-3 
STANLEY, R. G.; LINSKENS, H. F. Pollen: biology, biochemistry, management. Berlin: SpringerVerlag, 1974. https://doi.org/10.1007/978-3-64265905-8

STANSKI, C. Catálogo polínico de espécies de Myrtaceae e Solanaceae da Região dos Campos Gerais - Paraná, Brasil. 2014. 183 f. Dissertação (Mestrado em Engenharia Florestal) Universidade Federal do Paraná, Curitiba. 2014.

VIEIRA, C. T. Morfologia e viabilidade de grãos de pólen armazenados de Toona ciliata M. Roemer. 2013. 51 f. Dissertação (Mestrado em Engenharia Florestal) - Universidade Federal de Lavras, Minas Gerais. 2013.

VIGNOLI-SILVA, M.; BATISTA-FRANKLIM, C. P. R.; CORREA, D. S. M.; MENTZ, L. A.; MENDONÇA, C. B. F.; GONÇALVES-ESTEVES, V. Pollen diversity in Cestrum L. (Solanaceae) from extra-Amazonian Brazil. Palynology, v.39, n.1, p. 76-90, 2015.

https://doi.org/10.1080/01916122.2014.936982

VOLK, G. M. Collecting pollen for genetic resources conservation. In: Guarino, L.; Rao, R. V.; Goldberg, E. Collecting plant genetic diversity: technical guidelines - 2011. Rome: Bioversity International, 2011. p. 1-10.

ZINN, K. E.; TUNC-OZDEMIR, M.; HARPER, J. F. Temperature stress and plant sexual reproduction: uncovering the weakest links. Journal of Experimental Botany, v. 61, n.7, p. 1959-1968, 2010.

https://doi.org/10.1093/jxb/erq053

YBERT, J. P.; SALGADO-LABOURIAU, M. L.; BARTH, O. M.; LORSCHEITTER, M. L.; BARROS, M. A.; CHAVES, S. A. M.; LUZ, C. F. P.; RIBEIRO, M.; SCHEEL, R.; VICENTINI, K. R. F. Sugestões para padronização da metodologia empregada para estudos palinológicos do quaternário. Revista do Instuto Geológico, v.13, n.2, p. 47-49, 1992.

https://doi.org/10.1093/jxb/erq053 